\section{Chomsky's revolution}

Neil Smith

The Linguistics Wars. By Randy Allen Harris. Oxford University Press: 1993. Pp. 356. $£ 22, \$ 30$.

NOAM Chomsky's position in the history of ideas is comparable to that of Darwin or Descartes. In this century his peers in influence are the unlikely trio of Einstein, Picasso and Freud, with each of whom he has something in common. Like Darwin and Descartes, Chomsky has redefined our understanding of ourselves as humans; like Freud - but with added intellectual rigour - he has revolutionized our view of the mind; like Einstein, he blends intense scientific creativity with radical political activism; like Picasso, he has overturned and replaced his own established systems with startling frequency. That a book on the history of linguistics should be reviewed in Nature is ultimately due to the fact that Chomsky's work has brought the study of language from the impressionism of the humanities into the scientific fold.

Apart from its direct effect on linguistics, Chomsky's work has had a major influence on philosophy and psychology, and a minor but not insignificant effect on a range of disciplines from anthropology to mathematics, from education to literary criticism. To understand this pervasive influence presupposes a grasp of the defining characteristics of Chomsky's programme, which combines mentalism, rationalism, genetic determination and the psychological reality of the constructs he postulates. Although behaviourists eschewed any appeal to the mental as being irremediably unscientific, contemporary psychology - of which linguistics forms a part - is based firmly on the causal efficacy of beliefs and desires. Moreover, what underpins this mentalism is a version of Cartesian rationalism that ascribes massive innate cognitive structure to the neonate. Appealing to arguments both from the poverty of the stimulus and universal properties of natural (human) languages, Chomsky has reinstated an epistemology that had seemed extinct, and in doing so he has produced explanatory theories that are making possible an understanding of the nature of language and, most importantly, how language is acquired.

One core idea of this current work, known as "principles and parameters theory', is that humans are innately endowed with a set of universal principles

that constrain the development of language. That is, the putative hypothesis space of the infant language-learner includes so few possibilities that the task of language acquisition is dramatically simplified. For instance, the principle of 'structure dependence' ensures that no child will ever entertain the hypothesis that one way of relating sentences is to reverse their word order, so that the question (or negative, or future tense) of

\section{IMAGE UNAVAILABLE FOR COPYRIGHT REASONS}

"Chomsky's work has brought the study of language from the impressionism of the humanities into the scientific fold."
'Chomsky demolished behaviourist psychology' might be 'psychology behaviourist demolished Chomsky'. Some of these universal principles are 'parametrized', allowing limited and antecedently specified variation from language to language, reducing the child's task in learning the possible structure of its first language to that of selecting the values exhibited by the ambient language. As in the case of immunology, linguistics has graduated in a generation from an instructive to a selective mode.

The value of Harris's outstanding, if overly ornate, book is that it shows how we have come to where we are. He documents in meticulous detail, with great sensitivity and unswerving impartiality, how Chomsky's early theories captured the imagination of the new generation of

cognitive scientists and resulted in the overthrow of Bloomfieldian linguistics and behaviourist psychology more generally. He explains the elegance of 'deep structure' and the power of Chomsky's conception of language as expounded in the 'standard theory', and then shows how a disparate group of young scholars, the generative semanticists, effectively hijacked the fledgling theory and developed it in ways so radical that Chomsky soon came to be seen as a reactionary fighting a rearguard action against the forces of progress.

The sequel to this apparent decline was remarkable. After a decade of academic savagery in which the discipline was severely factionalized, it was Chomsky rather than the young Turks who emerged victorious. His success was due in part to the awesome power of his rhetoric, but much more to the equally awesome power of his positive new ideas. While his rivals appeared to be floundering in a morass of new and unconstrained rule types, Chomsky developed a set of conditions on rules of grammar, which eliminated the perceived excesses of the theory, and which have culminated in the 'minimalist programme'. The success of the principles and parameters framework, allowing at last for a possible explanation of the mystery of language acquisition, has excited a new generation of cognitivists just as his work of the 1950s and 1960s had excited the old.

Harris has captured the flavour and the fervour of the debates to perfection. His account of these battles is of interest because it sheds light on the emergence and development of ideas now seen to be seminal. Just as details of the manoeuvres in the battle of Borodino are important for what they reveal about Napoleon, the individual skirmishes reported here are valuable for what they reveal about Chomsky and for casting light on a crucial episode in the history of ideas. Much recent historiography of linguistics is blighted by misrepresentation or bigotry, but as an eyewitness of the events depicted, I can vouch for the accuracy and fairness of Harris's dissection. He reports that both Chomsky and George Lakoff (the most visible and voluble of the generative semanticists) are, despite all his endeavours, in 'violent disagreement' with the substance of the book. They should rather be content. Harris has achieved the near impossible: being fair to both sides in a civil war.

Neil Smith is in the Department of Phonetics and Linguistics, University College London, Gower Street, London WC1E 6BT, UK. 